(c) American Dairy Science Association, 2003.

\title{
A Comparison of the Buttermilk Solids Functional Properties to Nonfat Dried Milk, Soy Protein Isolate, Dried Egg White, and Egg Yolk Powders
}

\author{
P. Y. Y. Wong and D. D. Kitts \\ Food, Nutrition and Health, Faculty of Agricultural Sciences \\ The University of British Columbia, Vancouver, BC, Canada
}

\begin{abstract}
Physicochemical (i.e., sulfhydryl group, protein, and total solubility) as well as functional properties (i.e., water-holding and fat-absorption capacity, foaming and emulsification capacity, and stability) of commercial buttermilk solids (BMS) were compared to nonfat dried milk, soy protein isolate, and dried egg yolk and egg white powders on an equivalent protein basis. BMS showed limited functional properties in water-holding capacity ( $0.75 \mathrm{~g}$ water/g protein) and fat-absorption capacity (1.2 g of oil/g of protein), and foaming capacity $(0.5 \mathrm{ml}$ of foam $/ \mathrm{ml}$ of solution) and stability. However, emulsifying capacity and stability of BMS was not significantly different from other dried protein powders. Results indicated that $0.9 \mathrm{~g}$ of protein (approximately $0.45 \%, \mathrm{wt} / \mathrm{vol}$, concentration) from BMS was needed to emulsify a maximum oil concentration of $50 \%$ in water at temperatures up to $50^{\circ} \mathrm{C}$. Denaturation of protein, quantified by free sulfhydryl groups, was a critical factor affecting the functionality of BMS and all other protein powders tested. The milk fat globule membrane present in BMS did not enhance either emulsifying capacity or stability.
\end{abstract}

(Key words: buttermilk solids, nonfat dried milk, soy protein isolate, egg powder)

Abbreviation key: BMS = buttermilk solids, DEW = dried egg white, $\mathbf{D E Y}=$ dried egg yolk, $\mathbf{E C}=$ emulsifying capacity, $\mathbf{E S}=$ emulsifying stability, $\mathbf{F A C}=$ fat-absorption capacity, $\mathbf{F C}$ = foaming capacity, $\mathbf{F S}$ = foam stability, $\mathbf{M F G M}=$ milk fat globule membrane, $\mathbf{N F D M}=$ nonfat dried milk, o/w $=$ oil in water, $\mathbf{S P I}=$ soy protein isolate, $\mathbf{W H C}=$ water-holding capacity.

\section{INTRODUCTION}

The churning of cream during butter-making produces both butter and an aqueous liquid byproduct com-

Received July 18, 2002.

Accepted September 12, 2002.

Corresponding author: D. D. Kitts; e-mail: ddkitts@interchange. ubc.ca. monly known as buttermilk. The spray-dried form of buttermilk, also known as buttermilk solids (BMS), has limited applications in food processing (Rajor et al., 1983; Malin et al., 1994). However, the reutilization of BMS as a nutritional or functional food ingredient could enhance the economical value of this byproduct as well as reduce the cost of waste disposal (Rajor et al., 1983).

In general, the composition of BMS is similar to that of nonfat dried milk (NFDM), with the exception that a higher fat content and the presence of milk fat globule membrane (MFGM) exist with BMS (Malin et al., 1994; Mistry et al., 1996). MFGM is a lipid-protein complex consisting of $55 \%$ protein, $44 \%$ lipid, and a small amount of carbohydrate (Kanno, 1989). Earlier studies have shown that MFGM can act as a natural emulsifier in the reconstitution of milk fat globule emulsion (Kanno, 1989; Kanno et al., 1991) and in a butteroil emulsion (Oehlmann et al., 1994). Kanno (1989) showed that only $1 \%$ MFGM was needed to emulsify $25 \%$ milk fat (i.e., $40 \mathrm{mg}$ of MFGM/g of fat) and that the emulsion was stable within a temperature range of 4 to $55^{\circ} \mathrm{C}$, and at a $\mathrm{pH}$ of either 4 or between 6 and 9 . Further analysis revealed that the absorbed protein at the oilin-water $(\mathbf{o} / \mathbf{w})$ interface was the main component in MFGM responsible for the observed emulsification activity (Kanno et al., 1991). However, the presence of phospholipids can also enhance the emulsification activity by bridging between MFGM proteins at the $\mathrm{o} / \mathrm{w}$ interface (Fang and Dalgleish, 1996).

The potential utilization of industrial BMS as an emulsifying agent due to the MFGM content was first demonstrated by Corredig and Dalgleish (1998) using a soybean $\mathrm{o} / \mathrm{w}$ emulsion. A $1 \%$ concentration of BMS was reported to be effective at emulsifying a $10 \%$ soybean oil emulsion at $25^{\circ} \mathrm{C}$, and an increase in BMS concentration did not further increase emulsification capacity. In contrast, an increase in oil concentration decreased both the capacity and stability of the o/w emulsion (Corredig and Dalgleish, 1998). Furthermore, exposure of the o/w emulsion to an elevated temperature of $90^{\circ} \mathrm{C}$ for 3 min resulted in a higher concentration of BMS (i.e., greater than $8 \%$ ) required to stabilize a $10 \% \mathrm{o} / \mathrm{w}$ 
emulsion. Therefore, further data concerning the BMSoil ratio and the stability of BMS stabilized emulsion against various storage times and temperatures is needed to determine the emulsification activity of commercial BMS for potential use in formulated food products.

Buttermilk or BMS has also been shown to improve the organoleptic qualities of fabricated foods. For example, the addition of sweet buttermilk to soft-serve ice cream mix will improve the melting resistance and decrease both the coarseness and sandiness of frozen ice cream (Rajor et al., 1983). The protein content in ultrafiltrated buttermilk was beneficial at increasing the apparent viscosity and decreasing the acidity (i.e., buffering capacity) in nonfat/low-fat yogurt (Vani and Zayas, 1995), whereas the incorporation of ultrafiltrated buttermilk into reduced fat mozzarella and cheddar cheese enhanced the mouthfeel or body of the cheeses by improving meltability and increasing moisture content (Mistry et al., 1996; Poduval and Mistry, 1999). Our former study on commercial buttermilk also demonstrated a novel use of BMS as a natural antioxidant (Wong and Kitts, 2003). BMS appears to possess many functional properties beyond emulsification in fabricated foods.

Many commercially available protein powders are widely used for their functional properties such as foaming capacity [e.g., NFDM and dried egg white (DEW)], emulsifying capacity [e.g., dried egg yolk (DEY) and soy protein isolate] and water-holding capacity (WHC) [e.g., soy protein isolate (SPI)]. In an attempt to identify potential areas for the reutilization of the dairy byproduct BMS, this study was undertaken to compare the functional properties of BMS (i.e., foaming, fat, and water-binding capacity) NFDM, soy protein isolate (SPI), DEW, and DEY, and to characterize the emulsifying capacity of protein powders in response to various concentrations, oil-to-water ratio, storage times and temperatures.

\section{MATERIALS AND METHODS}

Spray-dried protein powders of BMS (35\% protein) and NFDM (35\% protein) were donated by Dairyworld Foods (Burnaby, BC). Soy protein isolate (91\% protein) and DEW (94\% protein) were purchased from a local specialty food store (Vancouver, BC). DEY (38\% protein) was obtained from Canadian Poultry Consultants. Canola oil was purchased from a local supermarket (Vancouver, BC). All chemicals used were of reagent grade and were purchased from either Fisher Scientific (Toronto, ON) or Sigma Aldrich (St. Louis, MO). Only distilled deionized water was used for experimentation.
Because all powders vary in their levels of protein, analysis of samples was conducted based on equivalent protein basis and not on total solids. All samples were analyzed in triplicates.

\section{Physicochemical Properties}

Sulfhydryl group. Sulfhydryl group content in samples was measured according to a modified procedure of Ellman (1959). An equivalent weight of $0.3 \mathrm{~g}$ of protein from each sample was dissolved in $2 \mathrm{ml}$ of sodium phosphate buffer $(0.1 \mathrm{M}, \mathrm{pH} 8)$ and diluted by $5 \mathrm{ml}$ of distilled deionized water. A $0.2-\mathrm{ml}$ aliquot of this protein solution was mixed with $0.02 \mathrm{ml}$ 5,5'-dithio-bis-2nitrobenzoic acid $(39.6 \mathrm{mg}$ in $10 \mathrm{ml}$ of $0.1 \mathrm{M}$ sodium phosphate at $\mathrm{pH}$ 7) and $1 \mathrm{ml}$ of distilled deionized water. The mixtures were vortexed and allowed to stand for 15 min before reading absorbance at $417 \mathrm{~nm}$. Sample blanks were also measured to correct for background interference at $417 \mathrm{~nm}$.

pH, protein and total solubility. A $5 \%$ protein solution was made in distilled deionized water, and the $\mathrm{pH}$ was measured with an Accumet $\mathrm{pH}$ meter (Fisher Scientific, ON). Protein solutions were centrifuged at $12,000 \times g$ for $15 \mathrm{~min}$ at $25^{\circ} \mathrm{C}$ and the supernatant was used for the analysis of protein solubility and total solubility.

Protein solubility of samples was measured from a 100-fold diluted supernatant by the Bradford protein assay. A $160-\mu$ l diluted sample or protein standard was thoroughly mixed with $40 \mu \mathrm{l}$ of Bradford Coomassie Brilliant Blue dye reagent. The mixture was allowed to stand at ambient temperature for $15 \mathrm{~min}$ and the absorbance at $595 \mathrm{~nm}$ was recorded. Protein concentration in samples was calculated based on a standard curve derived from bovine serum albumin.

Total solubility of samples was measured directly from a supernatant using an Abbe refractometer at a constant temperature, and the ${ }^{\circ}$ Brix was interpreted as total solubility of all components in the sample in distilled deionized water.

\section{Functional Properties}

Water-holding capacity. An equivalent weight of $1 \mathrm{~g}$ of protein from all protein powders was hydrated to a paste-like consistency with distilled deionized water and the WHC was determined according to the centrifugation method of AACC (AACC, 1981). WHC (g of water/g of protein) was calculated as $\mathrm{WHC}=\left(\mathrm{W}_{2}-\mathrm{W}_{1}\right) /$ $\mathrm{W}_{0}$, where $\mathrm{W}_{0}$ is the weight of protein, $\mathrm{W}_{1}$ is the weight of tube plus protein and $\mathrm{W}_{2}$ is the weight of tube plus the sediment.

Fat absorption capacity. An equivalent weight of $1 \mathrm{~g}$ of protein from all protein powders was thoroughly 
vortexed with $10 \mathrm{ml}$ of canola oil and the fat-absorption capacity (FAC) was determined according to the centrifugation method of Ahmedna et al. (1999). Fat absorption capacity ( $\mathrm{g}$ of oil/g of protein) was calculated as $\mathrm{FAC}=\left(\mathrm{W}_{2}-\mathrm{W}_{1}\right) / \mathrm{W}_{0}$, where $\mathrm{W}_{0}$ is the weight of protein, $\mathrm{W}_{1}$ is the weight of tube plus protein and $\mathrm{W}_{2}$ is the weight of tube plus the sediment.

Foaming capacity and stability. A 1.36-g protein solution from all samples, with DEW serving as the reference sample, was reconstituted to a total volume of $40 \mathrm{ml}$ with distilled deionized water, as well as a $0.68 \mathrm{~g}$ (1/2-fold) and $2.78 \mathrm{~g}$ (twofold) protein solution from BMS. DEY was not analyzed in this study because it possessed limited foaming capacity and stability. Protein solutions were blended on high speed for $3 \mathrm{~min}$ in a stainless-steel container using a Waring blender, and foaming capacity (FC) and stability (FS) were measured by the method of Ahmedna et al. (1999) in a glass graduated cylinder. Foaming capacity $(\mathrm{ml}$ of foam $/ \mathrm{ml}$ of initial liquid) and $\mathrm{FS}$ ( $\mathrm{ml}$ of liquid remaining in foam/ $\mathrm{ml}$ of initial liquid) was calculated as $\mathrm{FC}=\mathrm{V}_{\mathrm{f}} / \mathrm{V}_{\mathrm{i}}$ and $\mathrm{FS}$ $=\left(V_{i}-V_{0}\right) / V_{i}$, where $V_{0}$ is the volume of liquid generated beneath the foam, $V_{i}$ is the initial volume of solutions and $\mathrm{V}_{\mathrm{f}}$ is the volume of foam after blending.

Emulsifying capacity against protein and oil concentration. Emulsifying capacity (EC) was determined according to the centrifugation procedures of Ahmedna et al. (1999). Protein content between 0.3 and $5.4 \mathrm{~g}$ from all protein powders samples, with DEY serving as the reference sample, were analyzed for EC in a 50\% canola o/w emulsion at ambient temperature formed from homogenizing on high speed for $1 \mathrm{~min}$ in a stainless-steel container using a Waring blender. The optimal level of protein for emulsifying o/w emulsion (i.e., $1 \mathrm{~g}$ ) was selected for the determination of EC against various percentage of oil (ranging from 10 to $90 \%)$ in emulsion. EC was reported as $\mathrm{EC}(\%)=\left(\mathrm{V}_{\mathrm{f1}} /\right.$ $\left.V_{t}\right) \times 100$, where $V_{f 1}$ is the volume of emulsified fraction after centrifugation and $V_{t}$ is the volume of initial emulsion. DEW was not analyzed in this study since it is not typically used for emulsification.

Emulsifying stability against time and temperature. Emulsifying stability (ES) of $1 \mathrm{~g}$ of equivalent protein in a $25 \% \mathrm{o} / \mathrm{w}$ emulsion (made in the same manner as EC) over a period of $1 \mathrm{~h}$ was determined according to the turbidity method of Pearce and Kinsella (1978). A decrease in absorbance at $500 \mathrm{~nm}$ is interpreted as the destabilization of emulsion.

The emulsifying stability of $1 \mathrm{~g}$ of equivalent protein in a $50 \% \mathrm{o} / \mathrm{w}$ emulsion (made in the same manner as EC) at various temperatures was determined according to the centrifugation method of Ahmedna et al. (1999) after incubating the emulsion at $4,25,50$, and $75^{\circ} \mathrm{C}$ for $30 \mathrm{~min}$. The ES was reported as $\mathrm{ES}(\%)=\left(\mathrm{V}_{\mathrm{f2} 2} / \mathrm{V}_{\mathrm{t}}\right) \times 100$, where $V_{f 2}$ is the volume of emulsified fraction after heating and centrifugation and $V_{t}$ is the volume of initial emulsion.

Microscopy of emulsion. A 10\% o/w emulsion stabilized by $1 \mathrm{~g}$ of equivalent protein was observed for the size and distribution of the emulsified oil droplets under a light microscope. Microscopic examination of emulsion involved staining $1 \mathrm{ml}$ of emulsion with a drop of $0.1 \%$ congo red (water-soluble dye). Observations were made under 200× magnification using a light microscope (Universal Transmitted-Light Microscope: model Axioskop with camera attachment) and photographs of the emulsions were taken with $35 \mathrm{~mm}$ black and white film.

\section{Statistical Analyses}

All measurements were made in triplicates, and experiments were repeated once. All data were reported as mean \pm standard error of mean. Sample effects were analyzed by a one-way ANOVA, whereas sample and treatment effects (i.e., concentrations, oil-to-water ratio, storage times and temperatures) were analyzed by a two-way ANOVA using the MiniTab Statistical Software version 13.31 (MiniTab Corp. Inc., PA). Significant differences $(P<0.05)$ between means were identified by the Tukey's test in the same statistical software. A Pearson product moment correlation coefficient was also computed to determine relationships between the physicochemical properties of the protein powders and functional properties.

\section{RESULTS AND DISCUSSION}

\section{Physicochemical Properties}

Solubility is critical for protein functionality (Kinsella, 1976) and may affect other functionalities such as emulsification, gelation, and foam formation (Hettiarachchy et al., 1996). Many factors such as surface hydrophobicity, $\mathrm{pH}$, and ionic strength of solvent can influence protein solubility in solution (Wagner and Anon, 1990). In particular, $\mathrm{pH}$ affects the magnitude of the net charges on molecules, which in turn alters attractive and repulsive electrostatic interactions between protein-to-protein and protein-to-water (Wagner and Anon, 1990). At nonisoelectric $\mathrm{pH}$, a net charge greater than zero will ensure high protein solubility in the solvent. This event was observed for both BMS and NFDM in water (Table 1), whereas both SPI and DEY exhibited relatively poor protein solubility at nonisoelectric $\mathrm{pH}$. This finding, plus the lack of a significant correlation $(P>0.05)$ between $\mathrm{pH}$ and protein solubility, suggests other properties of protein affected solubility in water. Wagner and Anon (1990) have reported that 
Table 1. Some physicochemical properties of commercial protein powders. ${ }^{1}$

\begin{tabular}{lllll}
\hline Sample & $\mathrm{pH}$ & $\begin{array}{l}\text { SH group }^{2,3} \\
(\text { millimolar })\end{array}$ & $\begin{array}{l}\text { Protein solubility } \\
(\%)\end{array}$ & $\begin{array}{l}\text { Total solubility } \\
\left({ }^{\circ} \text { Brix }\right)\end{array}$ \\
\hline BMS & $6.5 \pm 0.0^{\mathrm{d}}$ & $0.07 \pm 0.01^{\mathrm{d}}$ & $33.6 \pm 7.7$ & $13.1 \pm 0.1^{\mathrm{b}}$ \\
NFDM & $6.6 \pm 0.0^{\mathrm{d}}$ & $0.08 \pm 0.01^{\mathrm{d}}$ & $34.6 \pm 3.5$ & $14.7 \pm 0.4^{\mathrm{a}}$ \\
SPI & $7.0 \pm 0.2^{\mathrm{b}}$ & $18.2 \pm 1.78^{\mathrm{a}}$ & $14.3 \pm 2.8$ & $2.0 \pm 0.1^{\mathrm{e}}$ \\
DEW & $6.8 \pm 0.1^{\mathrm{c}}$ & $1.60 \pm 0.55^{\mathrm{c}}$ & $18.0 \pm 1.3$ & $5.9 \pm 0.1^{\mathrm{d}}$ \\
DEY & $8.9 \pm 0.3^{\mathrm{a}}$ & $6.90 \pm 0.44^{\mathrm{b}}$ & $20.9 \pm 6.7$ & $9.2 \pm 0.5^{\mathrm{c}}$ \\
$P$-value $^{5}$ & 0.001 & 0.001 & 0.141 & 0.001 \\
\hline
\end{tabular}

${ }^{\mathrm{a}, \mathrm{b}, \mathrm{c}, \mathrm{d}, \mathrm{e}}$ Means in column with different letters are significantly different $(P<0.05)$.

${ }^{1}$ Mean \pm SEM $(n=6)$. BMS = Buttermilk solids, NFDM = nonfat dried milk, $\mathrm{SPI}=$ soy protein isolate, DEW = dried egg white, DEY = dried egg yolk.

${ }^{2}$ Parameters with similar superscripts have a correlation of $-0.977(P<0.05)$.

${ }^{3}$ Parameters with similar superscripts have a correlation of $-0.348(P<0.05)$.

${ }^{4}$ Parameters with similar superscripts have a correlation of $0.371(P<0.05)$.

${ }^{5} P$-values of sample effects on the parameters measured.

the sulfhydryl group in protein is related to insolubilization of soybean products and the degree of insolubilization increases with increasing free sulfhydryl groups. Our findings also indicate that free sulfhydryl groups were inversely correlated $(-0.997 ; P<0.05)$ to protein solubility and the increase in sulfhydryl groups in SPI and DEY (Table 1) was a likely factor responsible for the relatively lower protein solubility observed in these sources. This observation may be explained by the reduction of disulfide linkages to sulfhydryl groups accompanying the unfolding of a protein molecule, which in turn increases the hydrophobicity of SPI and DEY powder and lowers solubility in water. However, the relatively high abundance of sulfur amino acid in soy and egg yolk protein - and the relatively low abundance of sulfur amino acid in casein-may also be a factor for the increased free sulfhydryl groups detected.

The interaction between protein and carbohydrates, lipids, and other food components, can affect both the protein and total solubility of a protein powder. SPI, DEW, and DEY all exhibited a significantly $(P<0.05)$ lower total solubility in comparison to BMS and NFDM (Table 1). In all cases, the solubility of samples were found in the descending order of NFDM $>$ BMS $>$ DEY $>$ DEW $>$ SPI. Since the main component in our samples was protein, a significant $(P<0.05)$ correlation between an increase in protein solubility and an increase in total solubility is expected. This finding does not preclude the fact that other food components in the test samples in addition to protein also influenced total solubility.

\section{Functional Properties}

Water holding and fat-absorption capacity. The WHC of proteins has an important role in the physical (e.g., elasticity, swelling), chemical (e.g., emulsification) and sensory (e.g., juiciness) attributes of foods. SPI had the greatest WHC, followed by DEW, DEY, BMS, and NFDM (Table 2). A similar finding has been reported by Ahmedna et al. (1999) albeit the WHC of SPI was markedly less than that reported herein. Ahmedna et al. (1999) suggested that the greater WHC of SPI was due to partial denaturation, dissociation, and unfolding of protein induced by the heat treatment applied during preparation and drying. This assumption was confirmed in our study whereby the level of free sulfhydryl group of all samples followed a similar descending order of SPI $>$ DEY $>$ DEW $>$ BMS = NFDM (Table 1) seen with the WHC of all samples in Table 2. Moreover, a significant correlation of $0.976(P<0.05)$ was established between WHC and sulfhydryl group content. Inverse relationships between WHC and both types of solubility $(-0.408$ for protein solubility and -0.983 for total solubility, $P<0.05$ ) were also established in this study, which confirms the results of Wagner and Anon (1990) and Vani and Zayas (1995). This inverse relationship between WHC and solubility is best explained by the formation of a stable protein matrix from denatured protein, which entraps significant amount of water (Wagner and Anon, 1990).

Fat absorption capacity is the binding of fat by nonpolar amino acids present in the side chains of proteins (Susheelamma and Rao, 1974). The affinity of protein to bind fat improves the texture and reduces yield losses in fabricated foods such as comminuted meat or bakery products. According to Table 2, the order of FAC, in descending capacity was NFDM $>$ SPI $>$ DEY $>$ BMS $=$ DEW. Ahmedna et al. (1999) also found NFDM to have a greater FAC than SPI, but the FAC recorded were lower than those reported here. One explanation for the difference in FAC between samples is that NFDM had a slightly lower initial fat content than SPI, which therefore would result in an increase potential to bind more fat (Lin and Zayas, 1987). This explanation can 
Table 2. Water and fat binding capacity and related effects on foaming properties of commercial protein powders. ${ }^{1}$

\begin{tabular}{lllll}
\hline Sample & $\begin{array}{l}\text { WHC } \\
\text { g H} H_{2} \text { /g protein }\end{array}$ & $\begin{array}{l}\text { FAC } \\
\text { g fat/g protein }\end{array}$ & $\begin{array}{l}\text { Foaming capacity } \\
\text { ml foam/ml liquid }\end{array}$ & $\begin{array}{l}\text { Foaming stability }^{2} \\
\text { ml final liquid/ } \\
\text { ml initial liquid }\end{array}$ \\
\hline BMS & $0.85 \pm 0.13^{\mathrm{d}}$ & $1.17 \pm 0.04^{\mathrm{d}}$ & $0.38 \pm 0.03^{\mathrm{d}}$ & $0.02 \pm 0.01^{\mathrm{b}}$ \\
$\mathrm{NFDM}$ & $0.55 \pm 0.01^{\mathrm{e}}$ & $3.03 \pm 0.05^{\mathrm{a}}$ & $0.92 \pm 0.11^{\mathrm{c}}$ & $0.16 \pm 0.03^{\mathrm{a}}$ \\
SPI & $4.60 \pm 0.14^{\mathrm{a}}$ & $2.54 \pm 0.06^{\mathrm{b}}$ & $1.30 \pm 0.18^{\mathrm{b}}$ & $0.18 \pm 0.01^{\mathrm{a}}$ \\
$\mathrm{DEW}$ & $1.68 \pm 0.06^{\mathrm{b}}$ & $1.35 \pm 0.07^{\mathrm{d}}$ & $2.02 \pm 0.19^{\mathrm{a}}$ & $0.19 \pm 0.01^{\mathrm{a}}$ \\
DEY & $0.96 \pm 0.07^{\mathrm{c}}$ & $1.97 \pm 0.06^{\mathrm{c}}$ & $\mathrm{ND}^{4}$ & $\mathrm{ND}$ \\
$P$-value & $<0.001$ & $<0.001$ & $<0.001$ & $<0.001$ \\
\hline
\end{tabular}

a,b,c,d,e Means in column with different letters are significantly different $(P<0.05)$.

${ }^{1}$ Mean \pm SEM $(\mathrm{n}=6)$. WHC $=$ water-holding capacity, FAC-fat-absorption capacity, BMS = buttermilk solids, NFDM = nonfat dry milk, SPI = soy protein isolate, DEW = dried egg white, DEY = dried egg yolk.

${ }^{2}$ Foaming capacity and stability are measured based on a $1.36 \mathrm{~g}$ protein soloution.

${ }^{3} P$-values of sample effects on the parameters measured.

${ }^{4} \mathrm{ND}=$ Not determined.

be further extended to account for the lower FAC of BMS and DEY because these powders contained the highest level of fat among all samples. Another possible reason for the superior FAC of SPI can be explained by the significant level of sulfhydryl groups, which indicate a denatured and unfolded protein molecule with hydrophobic regions for interaction with fat. Surprisingly, the presence of MFGM in BMS did not enhance the FAC of BMS over NFDM, which has no MFGM content present. It appears, therefore, that dairy proteins (i.e., casein and whey) in milk powders have a greater role in fat absorption than MFGM specifically.

Foaming capacity and stability. Foaming is the incorporation of air into an aqueous medium by means of physical agitation and aeration. Protein foams are important to several categories of foods, including meringues, whipped toppings, and leavened bakery products. The primary functions of proteins in a foam is to decrease the interfacial tension at the air/liquid interface to facilitate the incorporation of air into the liquid phase and to stabilize the resulting foam by forming a cohesive film around the air droplets. Using an equivalent amount of protein, DEW was found to have the greatest foaming capacity, followed by SPI, NFDM, and BMS (Table 2). Former findings by Ahmedna et al. (1999) showed no differences in foaming capacity between DEW, SPI, and NFDM. However, the authors did not account for the difference in the protein content between the three protein solutions in their experiment. Nevertheless, an increase in protein content from BMS has been reported to have no effect on the foaming capacity (Sather et al., 1982). Therefore, several other physicochemical factors, such as protein solubility, surface charges, protein denaturation, surface hydrophobicity, size of protein, and flexibility of protein molecule also have been known to affect foaming capacity and stability (Kinsella, 1976).
Greater foam stability established by protein powders in the isoelectric region has been attributed to the low net charge that decrease intermolecular repulsions and the greater association of denatured protein molecules to foam a stable and cohesive film around air droplets (Zayas, 1997). In this study, the observed $\mathrm{pH}$ of DEW was near the isoelectric point of egg albumen protein and positively correlated to an increase in foaming capacity. However, protein molecules at isoelectric point are less soluble and protein solubility is a factor for to foaming capacity (Hettiarachchy et al., 1996; Ahmedna et al., 1999). NFDM was found to possess the greatest protein solubility but it also exhibited significantly less foaming capacity then SPI and DEW that had lower solubility. Furthermore, SPI exhibited relatively high foaming capacity at nonisoelectric $\mathrm{pH}$ and low solubility.

A more likely explanation for the difference in foaming capacities between sample proteins used in this study could be related to the significant $(P<0.05)$ relationship obtained between foaming capacity and sulfhydryl group content. The noted increase in sulfhydryl group of SPI reflected a greater denaturation and unfolding of the protein, and therefore, resulted in a greater surface hydrophobicity. Townsend and Nakai (1983) reported that proteins are extensively uncoiled at the air/water interface, and this is the major reason for the increased foaming capacity of proteins with relatively high surface hydrophobicity. Moreover, the extent by which denatured proteins unfold to adequately interact with the entire interface is also a critical factor in foaming capacity (Towsend and Nakai, 1983). The greater degree of surface hydrophobicity of DEW and SPI protein sources is a possible explanation for the observed relationship of the denatured polypeptides to form a continuous cohesive film around air droplets that are needed for foaming capacity and stability (Kinsella, 
1979). This feature would also explain the different foaming capacities noted with NFDM in this study. Globular proteins for example, found in Phaseolus mungo, have lower free sulfhydryl group content but can stabilize foam by readily unfolding at the air/water interface due to hydrophobicity and serve as a physical barrier to bubble coalescence (Trachoo and Mistry, 1998). Therefore, the presence of the MFGM may have displaced the proteins in BMS from the air/water interface, or interacted with the partially denatured proteins (through hydrophobic interactions) that are also required in foaming.

Similar to the findings of Ahmedna et al. (1999), the foaming stability of DEW, SPI, and NFDM were not statistically different $(P>0.05)$ despite the notable difference in foaming capacity (Table 2 ). Thus, formation of a stable protein layer at the interface does not assure foam stability, unless the protein is capable of forming strong intermolecular interactions that result in a desired cohesiveness (Kinsella et al., 1985). The partially denatured proteins of DEW, SPI, and NFDM were equally satisfactory in creating a monolayer that adequately covered the entire air/water interface, as well as stabilizing the air droplets with a cohesive monolayer. In addition, an increase in the viscosity of the foam will also enhance foam stability by reducing air leakage. This observation was particularly evident with the SPI sample, where a superior WHC corresponded to an increased foaming capacity and stability.

Emulsifying capacity and stability. An o/w emulsion is a suspension of fat droplets in water that is stabilized by a surface-active agent or emulsifier at the $\mathrm{o} / \mathrm{w}$ interface. Therefore, the ability of a protein to act as an emulsifier will depend primarily on its amphipathic nature, in addition to other factors such as solubility of protein, degree of surface denaturation, lipid-to-protein ratio, and its effect on emulsion viscosity. Because BMS contains various fractions capable of emulsification (e.g., MFGM, $\beta / \kappa$-casein, and whey proteins), the hypothesis that commercial BMS can act as a nature emulsifier was examined under various conditions of protein content, lipid-to-protein ratio, time, and temperature.

A two-way ANOVA revealed a significant $(P<0.05)$ sample and protein concentration effect on the emulsifying capacity of various test materials. In general, an optimal emulsifying capacity for all samples was achieved with only $0.9 \mathrm{~g}$ of protein (Figure 1a). Thus, a relatively small but adequate amount of protein was absorbed at the interface to suspend all the oil droplets created by $50 \%$ oil concentration, regardless of the shape and relative flexibility of the individual protein sources tested. Increasing the protein content did not further enhance emulsification capacity, since excess
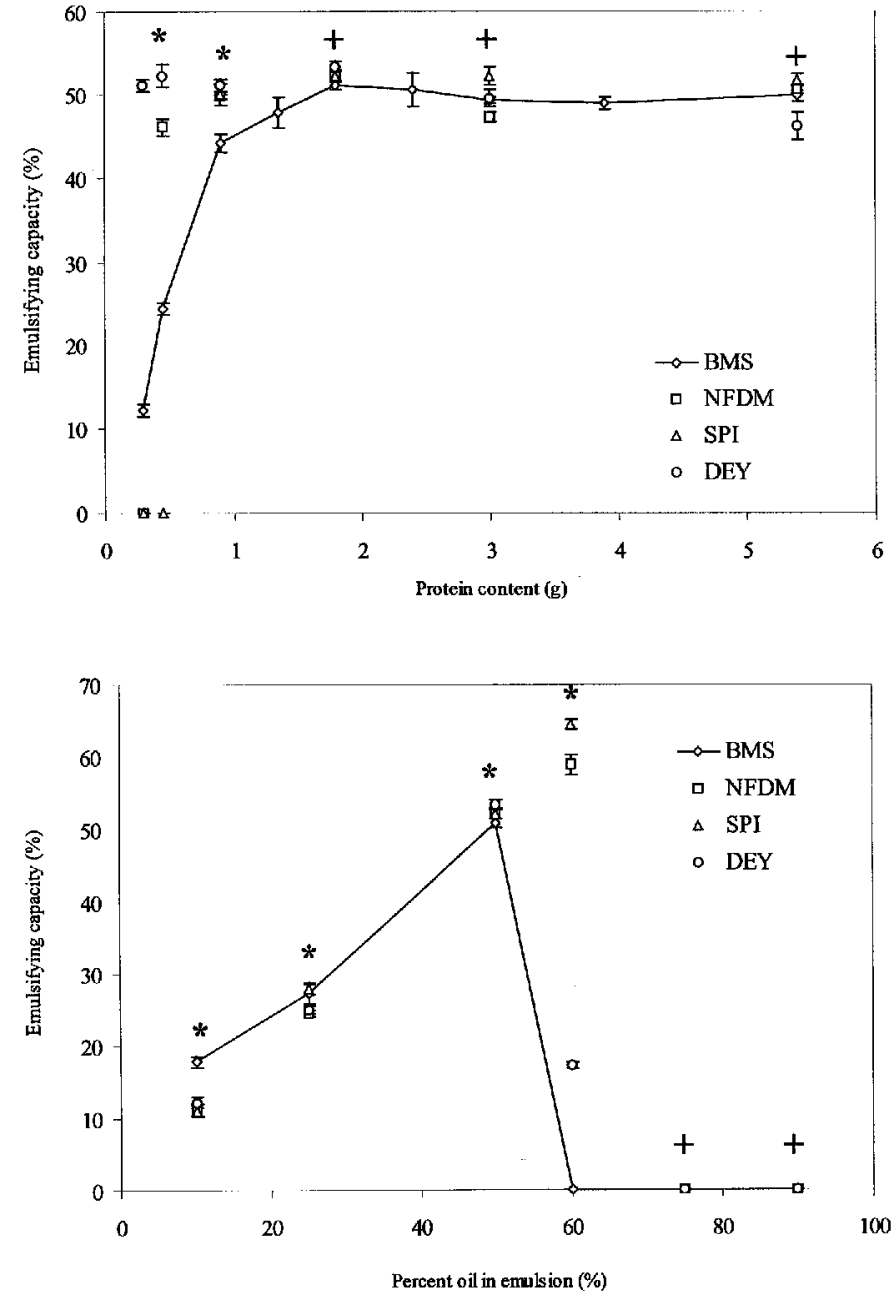

Figure 1. Emulsifying capacity of buttermilk solids (BMS) and commercial protein powders at various protein content (top figure) and percentage of oil (bottom figure) in a $50 \%$ oil/water emulsion. All data reported are mean \pm SEM. Top: $*$ Denotes significant difference $(P<0.05)$ among samples. ${ }^{+}$Denotes no significant difference $(P>$ $0.05)$ among all samples and no significant difference $(P>0.05)$ in emulsifying capacity in any sample between the protein content of 2.1 to $5.4 \mathrm{~g}$. Bottom: *Denotes significant difference $(P<0.05)$ between BMS and all other samples. ${ }^{+}$Denotes no significant difference $(P>$ 0.05 ) among samples. NFDM = Nonfat dry milk, $\mathrm{SPI}=$ soy protein isolate, $\mathrm{DEY}=$ dried egg yolk.

protein is unable to migrate to the $\mathrm{o} / \mathrm{w}$ interface. Therefore, an emulsification effect did not occur but rather a stabilization effect likely took place through a lipophilic-hydrophilic arrangement (Kanno et al., 1991). Identifying a significant difference $(P<0.05)$ in emulsifying capacity between samples was only noted between 0.3 to $0.9 \mathrm{~g}$ of protein. At low protein contents, both DEY and BMS exhibited better emulsifying capacity than SPI and NFDM. This result is contrary to the findings of Ahmedna et al. (1999), but can be explained by the greater emulsifying capacity of BMS resulting 
from the presence of MFGM that contributes additional emulsifying properties (Corriedig and Dalgleish, 1998; Kanno, 1991). Similarly, DEY contained amphipathic substances, such as lipoprotein and lecithin, also resulted in a relatively greater emulsifying capacity among all samples tested. The importance of hydrophobicity in emulsification is well known and the positive correlation $(P<0.05)$ obtained between sulfhydryl group and emulsifying capacity can be explained by the increased surface hydrophobicity, which further enhances the emulsification capacity of protein by increasing the attraction towards the o/w interface. Kanno et al. (1991) reported similar findings and concluded that the hydrophobic proteins and phospholipids in MFGM were responsible for the emulsification of fat globules in milk and cream.

In addition to hydrophobicity, the ionization of protein at various $\mathrm{pH}$ was also found to affect emulsifying capacity. Because both DEY and SPI have relatively higher $\mathrm{pH}$, the increased emulsifying capacity of these two powders could also be $\mathrm{pH}$ related. This observation is supported by the positive correlation of $(\mathrm{r}=0.525 ; P$ $<0.05$ ) observed between $\mathrm{pH}$ and emulsifying capacity; similarly reported by Sathe et al. (1982). The increase in $\mathrm{pH}$ towards alkalinity imparts a negative charge to the protein molecule, which facilitated emulsification by promoting protein-to-fat interaction and reducing protein-to-protein interaction through electrostatic repulsion (Susheelamma et al., 1974; Prinyawiwatkul et al., 1993).

A change in lipid-to-protein ratio was shown to affect the emulsifying capacity of all samples (Figure 1b). The greatest emulsifying capacity of BMS and DEY was achieved in a $50 \% \mathrm{o} / \mathrm{w}$ emulsion, and any changes in this proportion of oil resulted in a reduction in emulsification capacity. In situations in which low concentrations of oil exist, an excess of protein in the emulsion will favored protein aggregation rather than protein absorption at the $\mathrm{o} / \mathrm{w}$ interface through hydrophobic interactions. Aggregation of $\beta$-casein and the interaction with amphipathic substances, such as phospholipids, is a good example of the adverse effect of excess protein content on emulsion stability (Fang and Dalgleish, 1993). Moreover, the inverse correlation ( $\mathrm{r}=$ $-0.589 ; P<0.05)$ between WHC and emulsifying stability suggests an increased interaction between protein and water in the emulsion that has a low oil concentration (e.g., 10\%). By increasing the relative concentration of oil in the emulsion, an opposite phenomenon would be expected in which coalescence of the oil droplet reduces protein absorption at the interface, resulting from greater hydrophobic attraction between oil droplets. In the present study, SPI and NFDM were found to give a greater emulsifying capacity at $60 \%$ oil concentration.
This expected finding occurred since both SPI and NFDM had high FAC, due partially to a greater degree of surface hydrophobicity and sulfhydryl group content. Corredig and Dalgleish (1998) demonstrated that approximately $50 \%$ of the absorbed protein at the o/w interface from a BMS emulsion came from caseinates fractions, of which $\beta$-casein predominated due to its extremely hydrophobic nature. Thus, the relatively higher proportion of $\beta$-casein in the NFDM sample, compared with the BMS which also contained fat and MFGM, would explain why the NFDM had a greater emulsifying capacity than BMS. The absorption of casein, whey, and MFGM protein at the interface has also been shown to be dependent on the ratio of the three proteins present in the dairy powder (Corredig and Dalgleish, 1998).

The emulsifying stability of all protein samples was first measured in a $25 \%$ o/w emulsion by monitoring changes in turbidity over time. All absorbance readings recorded for the different samples tested in this study were higher than those reported by Pearce and Kinsella (1978), who used a similar method to study the emulsifying stability of $2 \%$ whey protein in a peanut oil emulsion. Among the samples tested, DEY was found to be the most effective at stabilizing the emulsion over a 60 min period, followed by NFDM, SPI and BMS (Figure 2a). The emulsifying stability of DEY occurred primarily from the rigidity of globular proteins that formed a highly cohesive film at the o/w interface and which can withstand mechanical deformation (Graham and Philips, 1976). The more flexible $\beta$-casein protein structure produced a weaker protein film at the interface and lower emulsion stability. In addition, the presence of elongated membrane-spanning protein fractions of MFGM, coupled to the flexible $\beta$-casein in the BMS, explains the lower emulsion stability observed for BMS (Corredig and Dalglesih, 1998). Regardless of the rigidity of the protein film, a minor destabilization of the emulsion was observed approximately $30 \mathrm{~min}$ after initial formation; albeit the emulsion remained stable thereafter. This minor flocculation or coalescence of oil droplet was greatest in the DEY stabilized emulsion, indicating that globular proteins are relatively less effective than flexible protein at reducing aggregation of oil droplet.

A strong correlation $(0.922, P<0.05)$ between emulsion stability over time and $\mathrm{pH}$ was also established in this study. Pearce and Kinsella (1978) reported an increased instability of a whey protein stabilized emulsion at $\mathrm{pH}$ values over 5.5. The emulsifying stability of MFGM in reconstituted milk fat was also enhanced under alkaline condition (Kanno, 1989). The apparent destabilization of emulsions under acidic condition observed in the present study and in others, is caused by 

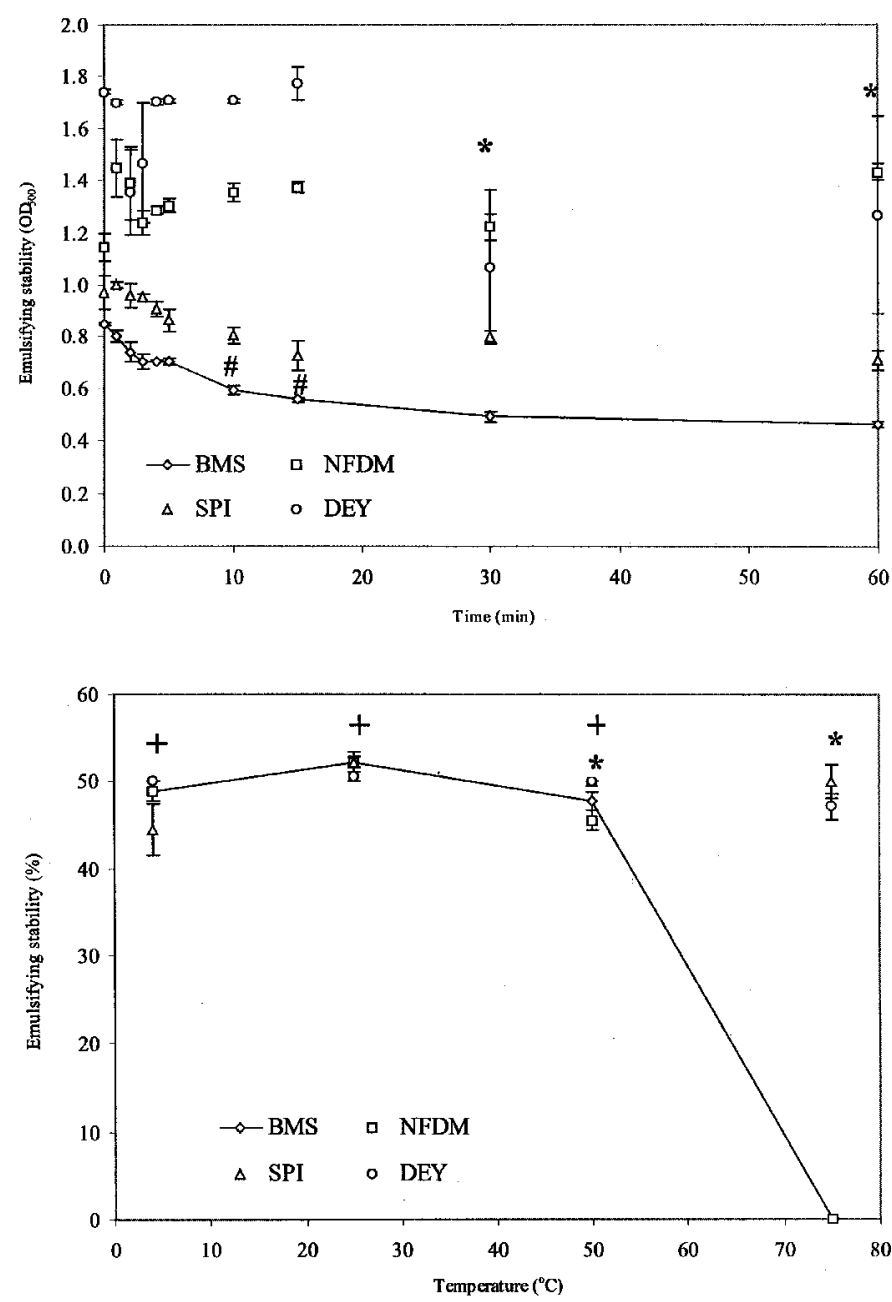

Figure 2. Emulsifying stability of buttermilk solids (BMS) and commercial protein powders in both a $25 \%$ oil/water emulsion over time (top) and a 50\% oil/water emulsion incubated at different temperatures (bottom). All data reported are mean \pm SEM. Top: All samples are significantly different $(P<0.05)$. *Denotes significant difference $(P<0.05)$ of values ranging from 0 to $15 \mathrm{~min}$ for all samples. "Denotes significant difference $(P<0.05)$ of values ranging from 0 to 5 min for BMS sample only. Bottom: *BMS and nonfat dried milk (NFDM) are significantly different $(P<0.05)$ from all other samples. ${ }^{+}$Values in all samples are not significantly different $(P>0.05)$ between the temperatures of 4 and $50^{\circ} \mathrm{C}$. SPI $=$ Soy protein isolate, $\mathrm{DEY}=$ dried egg yolk.

the aggregation of absorbed protein at the $\mathrm{o} / \mathrm{w}$ interface near the isoelectric points of $\mathrm{pH} 4$ to 5 for both plant and dairy proteins, which exposes the oil droplets surface for flocculation leading to de-emulsification (Kanno, 1989).

An increase in kinetic energy, in the form of heat, should also increase the random collision and flocculation of suspended oil droplets in an emulsion. After 30 min of exposure of test emulsions to temperatures between 4 and $50^{\circ} \mathrm{C}$, no difference in emulsion stability between the samples was observed (Figure 2b). Kanno (1989) reported stability of a MFGM emulsion between

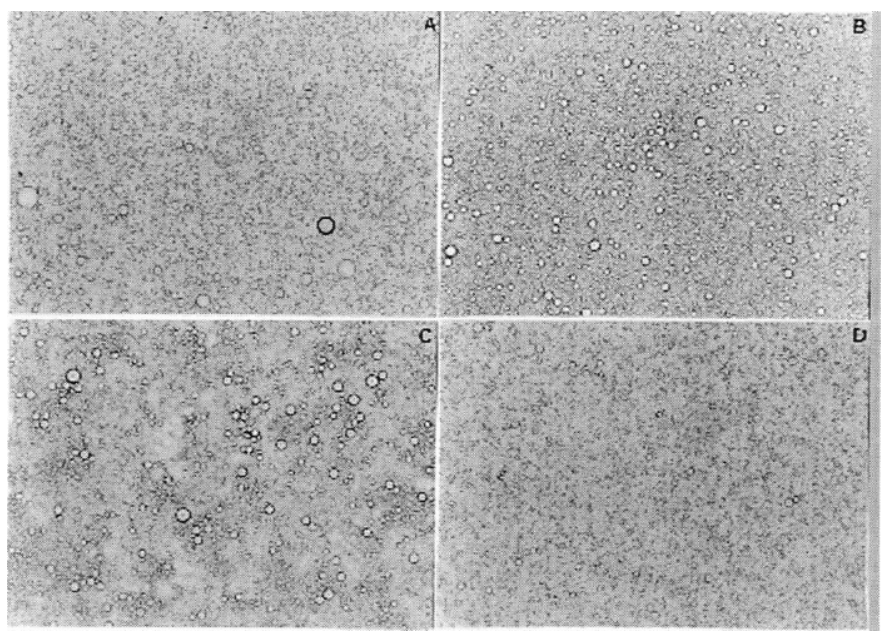

Figure 3. Photomicrograph of a $10 \%$ oil/water emulsion stabilized by buttermilk solids (A), nonfat dried milk (B), soy protein isolate (C), and dried egg yolk (D) at $200 \times$ magnification.

a temperature range of 4 and $55^{\circ} \mathrm{C}$. A temperature increase to $75^{\circ} \mathrm{C}$ in this study led to the destabilization of BMS and NFDM stabilized emulsions. This result is contradictory to the findings of Ahmedna et al. (1999), where a 50\% emulsifying stability of NFDM stabilized emulsion was found after heating at $90^{\circ} \mathrm{C}$ for $30 \mathrm{~min}$. The instability of BMS stabilized emulsion against high temperatures has also been reported by Corredig and Dalgleish (1998), who suggested that the bridging of oil droplets by absorbed BMS proteins at the interface resulted in a loss of emulsion. SPI and DEY were most resistant to the destabilization effect at elevated temperatures, since globular proteins are generally more stable to heat. In addition, a significant correlation between emulsion stability of SPI and DEY and both sulfhydryl group (0.841, $P<0.05)$ and total solubility $(-0.864, P<0.05)$ suggests that the hydrophobic interaction between protein and fat was a crucial factor in keeping the oil droplet suspended. A decrease in solubility of these protein sources would assure that the majority of the proteins remain absorbed at the interface at all temperatures.

Microscopy of emulsion. Microscopic examination of different test emulsions at 200× magnification revealed that all samples were effective at facilitating the formation of small and uniformity distributed oil droplets (Figure 3). Among the four samples tested, DEY appeared to produce the smallest oil droplets, followed closely by BMS, NFDM, and SPI. Furthermore, minor clustering of oil droplets were seen in both the SPI and BMS stabilized emulsions. This result implies that both SPI and BMS were effective in facilitating the emulsification of oil droplets, but less effective at 
stabilizing the emulsion. This empirical finding of emulsion stability coincides with the volumetric finding of emulsion stability of SPI and BMS over time.

\section{CONCLUSION}

BMS was demonstrated to possess limited functional properties beyond emulsification capacity, compared with NFDM, DEW, and DEY. The degree of protein denaturation, represented by the free sulfhydryl group, was closely related to the functional properties examined in this study. Hydrophobicity of denatured protein enhanced FAC, foaming capacity and stability, as well as emulsifying capacity and stability. WHC of protein also enhanced the foaming capacity and stability by increasing viscosity of the foam. However, hydrated protein was less effective at forming and stabilizing $\mathrm{o} / \mathrm{w}$ emulsion because of a decreased tendency to be absorbed onto the $\mathrm{o} / \mathrm{w}$ interface. Incorporation of MFGM in the form of BMS during blending did not enhance the volume and stability of the resulting foam. Emulsifying capacity was found to be influenced by either $\mathrm{pH}$ or surface charge of protein and protein-tooil ratio when both parameters strongly dictate establishment of either a protein-to-protein or protein-to-fat interaction. Emulsion stability was strongly affected by the type of protein present, as well as the surface charges of the absorbed proteins. The presence of MFGM in BMS did not enhance the functional properties of BMS over that observed for NFDM. The ratio between the casein, whey, and MFGM content in BMS likely determines its functional properties.

\section{REFERENCES}

AACC. 1981. Method for water hydration capacity of plant protein material. 26:291-293.

Ahmedna, M., W. Prinyawiwatkul, and R. Rao. 1999. Solubilized wheat protein isolate: Functional properties and potential food applications. J. Agric. Food Chem. 47:1340-1345.

Corredig, M., and D. G. Dalgleish. 1998. Buttermilk properties in emulsions with soybean oil as affected by fat globule membranederived proteins. J. Food Sci. 63:476-480.

Ellman, G. L. 1959. Tissue sulfhydryl group. Arch. Biochem. Biophys. 82:70-77.

Fang, Y., and D. G. Dalgleish. 1993. Casein adsorption on the surfaces of oil-in-water emulsions modified by lecithin. Colloids Surfaces B. 1:357-364.

Fang, Y., and D. G. Dalgleish. 1996. Competitive adsorption between dioleoylphosphatidylcholine and sodium caseinate on oil-water interfaces. J. Agric. Food Chem. 44:59-64.
Graham, D. E., and M. C. Philips. 1976. The conformation of proteins at the air-water interface and their role in stabilizing foam. Page 237 in Foams. R. J. Akers,ed. Academic Press, London.

Hettiarachchy, N. S., V. K. Griffin, and R. Gnanasambandam. 1996. Preparation and functional properties of a protein isolate from defatted wheat germ. Cereal Chem. 73:364-367.

Kanno, C. 1989. Emulsifying properties of bovine milk fat globule membrane in milk fat emulsion: conditions for the reconstitution of milk fat globules. J. Food Sci. 54:1534-1539.

Kanno, C., Y. Shimomura, and E. Takano. 1991. Physicochemical properties of milk fat emulsions stabilized with bovine milk fat globule membrane. J. Food Sci. 56:1219-1223.

Kinsella, J. E. 1976. Functional properties of proteins in foods: A survey. CRC Crit. Rev. Food Sci. Nutr. 7:219-280.

Kinsella, J. E. 1979. Functional properties of soy protein. J. Am. Oil Chem. Soc. 56:242-248.

Kinsella, J. E., S. Damodaran, and B. German. 1985. Physicochemistry and function of oilseed proteins. Pages 156 in New Protein Foods. A. M. Altschul and H. L. Wilcke, ed. Academic Press: New York.

Lin, C. S., and J. F. Zayas. 1987. Functionality of defatted corn germ proteins in a model system: fat binding capacity and water retention. J. Food Sci. 52:1308-1311.

Malin, E. L., J. J. Basch, J. Shien, B. C. Sullivan, and V. H. Holsinger. 1994. Detection of adulteration of buttermilk powder by gel electrophoresis. J. Dairy Sci. 77:2199-2206.

Mistry, V. V., L. E. Metzger, and J. L. Maubois. 1996. Use of ultrafiltered sweet buttermilk in the manufacture of reduced fat cheddar cheese. J. Dairy Sci. 79:1137-1145.

Oehlmann, S. M., S. E. Duncan, and T. W. Keenan. 1994. Butteroil emulsification with milk-derived membrane and protein fractions. J. Food Sci. 59:53-56, 66.

Pearce, K. N., and J. E. Kinsella. 1978. Emulsifying properties of proteins: evaluation of a turbidmetric technique. J. Agric. Food Chem. 26:716-723.

Poduval, V. S., and V. V. Mistry. 1999. Manufacture of reduced fat mozzarella cheese using ultrafiltered sweet buttermilk and homogenized cream. J. Dairy Sci. 82:1-9.

Prinyawiwatkul, W., L. R. Beuchay, and K. H. McWatters. 1993. Functional property changes in partially defatted peanut flour caused by fungal fermentation and heat treatment. J. Food Sci. 58:1318-1323.

Rajor, R. B., S. K. Gupta, A. A. Patel, and G. R. Patel. 1983. A new "softy" from buttermilk and soybean. Ind. Dairyman 35:29-32.

Sathe, S. K., S. S. Deshpande, and D. K. Salunkhe. 1982. Functional properties of winged bean [Psophocarpus tetragonolobus (L.) DC] proteins. J. Food Sci. 47:503-509.

Susheelamma, N. S., and M. V. L. Rao. 1974. Surface-active principle in black gram (Phaseolus mungo) and its role in the texture of leavened foods containing legume. J. Sci. Food Agric. 25:665-670.

Townsend, A. A., and S. Nakai. 1983. Relationship between hydrophobicity and foaming characteristics of food proteins. J. Food Sci. 48:588-594.

Trachoo, N., and V. V. Mistry. 1998. Application of ultrafiltered sweet buttermilk and sweet buttermilk powder in the manufacture of nonfat and low fat yogurts. J. Dairy Sci. 81:3163-3171.

Vani, B., and J. F. Zayas. 1995. Wheat germ protein flour solubility and water retention. J. Food Sci. 60:845-848.

Wagner, J. R., and M. C. Anon. 1990. Influence of denaturation, hydrophobicity and sulfhydryl content on solubility and water absorbing capacity of soy protein isolates. J. Food Sci. 55:765-770.

Wong, P. Y. Y., and D. D. Kitts. 2003. Chemistry of buttermilk solid antioxidant activity. J. Dairy Sci. 86:(In press).

Zayas, J. F. 1997. Functionality of Proteins in Foods. Springer-Verlag, Berlin, Germany. 